\title{
The Impact of Perception toward the Built Environment in Airport Access Mode Choice Using Hybrid Choice Modeling
}

\author{
Mahdi Yazdanpanah ${ }^{1}$ and Mansour Hadji Hosseinlou ${ }^{2}$ \\ ${ }^{1}$ Transportation Engineering, K. N. Toosi University of Technology, Tehran, Iran \\ ${ }^{2}$ Department of Civil Engineering, K. N. Toosi University of Technology, No. 1346, Vali Asr Street, Mirdamad Intersection, Tehran, Iran \\ Correspondence should be addressed to Mahdi Yazdanpanah; myazdanpanah@mail.kntu.ac.ir
}

Received 2 September 2016; Revised 18 October 2016; Accepted 7 November 2016; Published 16 January 2017

Academic Editor: Zhi-Chun Li

Copyright (c) 2017 M. Yazdanpanah and M. Hadji Hosseinlou. This is an open access article distributed under the Creative Commons Attribution License, which permits unrestricted use, distribution, and reproduction in any medium, provided the original work is properly cited.

\begin{abstract}
Built environment (BE), as an objective variable, plays a substantial role in urban residents' behavior. However, the perception toward a BE, as a subjective variable, varies among people. To identify the role of perception toward BE, we used a stated preference (SP) survey conducted in January-February 2015 at the Imam Khomeini International Airport (IKIA), Tehran, Iran. The data was drawn from 641 individuals; 359 of them were residents of Tehran. For the estimation of the model, a hybrid discrete choice model was used to capture the latent variable, in addition to mode attributes and trip conditions, with 1795 SP observations. Psychometric questions concerned the perception of ease in access to main streets or highways and good traffic conditions within their residential areas. The results showed that the latent variable (positive perception toward built environment or PBE) had a significant positive effect on people's willingness to park at the airport. Moreover, the gender, age, marital status, level of education, experience living in a foreign country, and income level also influenced the formation of perception toward the BE and airport transportation mode choice.
\end{abstract}

\section{Introduction}

Previous studies regarding built environment (BE) and transportation mode choice indicate that higher population densities, better local transport accessibility, and more choice diversity often result in less car and more public transport usage [1]. However, not all people perceive their BE in the same way, and their perceptions are subject to various behavioral influences $[2,3]$.

Many studies considered the objective effects of a $\mathrm{BE}$, but there is little work available that focused on attitudinal and perceptional behavior toward the BE $[1,4,5]$. There are excellent studies that capture psychometrical variables affecting active travel preferences, such as walking and cycling [610], but little research exists that analyzes the psychometric effects of BE, particularly the influence of perceptions toward $\mathrm{BE}$ on access to the airport. Therefore, this study investigated the simultaneous effects of perception toward BE and airport access mode choice.
For this purpose, we conducted a survey at Imam Khomeini International Airport (IKIA) during January-February 2015. The airport is located 30 kilometers (19 miles) southwest of Tehran and was designed to replace the Mehrabad International Airport (MIA), which is now inside Tehran's city boundaries [11]. Currently, IKIA serves only international flights with one passenger terminal, consisting of a total annual handling capacity of 6.5 million passengers. However, a second terminal for the pilgrimage flights is currently under construction. IKIA's capacity has grown impressively from 2005 to 2014 with an average annual growth rate of $23 \%$ [12]. Airport access from Tehran is currently provided only by hired cars-either taxis or vans or private cars-parked at the airport or using passenger drop-off. Currently, there are two car parking options at IKIA: a covered parking area near the terminal, which is fully occupied during peak hours, or outdoor parking areas, from which passengers are ferried to and from the passenger terminal by a free bus service [11]. Plans for an extension of the southern part of Tehran's metro 
train line 1 to access IKIA are under construction, and a long-term plan exists to add a new metro line 3-an express line-directly to IKIA [13]. However, neither of those metro lines are currently available, and no other plans for other transportation modes, such as a bus line, exist. Currently, air passengers can use metro line 1 to reach the nearest available station to IKIA (Shahed station) and take a taxi from there to the airport.

Tehran, the capital of Iran, has a population of about 8.3 million [14], which positions Tehran as the 16th largest city in the world ranked by population density [15]. Tehran occupies a mountainside with an altitude of 900 to 1700 meters above sea level. A vast network of highways, interchanges, ramps, and loops serves Tehran [16]. The concentration of so many people and their activities in Tehran cause significant transportation problems. Therefore, Tehran suffers from significant economic, social, and environmental challenges [17]. However, the major environmental issue in Tehran is air pollution [18], and Tehran's environmental quality score in 2006 was $56.5 \%$, or "middle ranking." Additionally, Tehran achieved a score of $61 \%$ for built environmental needs [19].

With these characteristics and challenges in mind, our primary focus in this study was on how Tehran's air passengers perceive their $\mathrm{BE}$ and to analyze the BE's effects on transportation access mode choices to the IKIA. We chose a recent modeling framework called hybrid choice modeling (HCM) to evaluate access mode choice. Ultimately, the findings of this study provided a more in-depth understanding of behavioral decisions regarding transportation mode choice, which could assist transportation policy makers and airport planners, particularly in a developing country like Iran.

The remainder of this paper is structured in five sections. In Section 2, we described previous literature regarding airport access mode choice and BE. In Sections 3 and 4, we explained the modeling framework and formulations for incorporating a psychometric variable (perception toward $\mathrm{BE})$ into the choice process, our case study, the data, and a description of the psychometric variable. In Section 5, we reported the modeling results, and, in Section 6, we provided a summary of our findings and avenues for future research.

\section{Background}

2.1. Literature Review Regarding Airport Access Mode Choice. Multiple studies have been conducted regarding airport access modes over the past four decades, which is due to the importance of the connection between the fastest means of transportation and ground transportation modes. Different aspects of travel time (total time, out of vehicle, in vehicle, and waiting time) and/or access costs have been evaluated as primary attributes in a majority of studies [2033]. While travel time and cost remain significant variables within previous transportation evaluation models, with the exception of socioeconomic variables, disparate studies also found other significant attributes, including flight frequency and frequency of service [20, 21]; luggage (passengers' amount of luggage, convenience in storing luggage, and airport luggage storage capacity) [20, 22, 23, 34]; the userfriendly nature of the modal and safety [24, 34]; nationality
[22]; and trip purpose (in a majority of studies). Therefore, previous studies provided insight into the factors affecting air passengers' choices regarding airport access modes, but almost all of these studies used observable variables to define passengers' preferences. For example, if safety or convenience are psychometric variables, these studies tended to consider them as observable variables and input them directly into the utility function. Another example of related work that psychometrically assessed airport passengers' preferences was performed using segmentation analysis, which was based on attitude statements of the Theory of Planned Behavior and Norm-Activation Theory at Manchester Airport [35]. The results of this study indicated that two groups, "Conflicted Greens" and the "Pessimistic Lift Seekers," had the greatest potential to reduce private car use to airports [35].

Therefore, there is a gap in the literature concerning the use of psychological variables (latent variables) within evaluation of the choice process. Regarding the analysis of the effect of psychological variables on transportation mode choice, we previously analyzed the influence of personality traits on mode choice to IKIA using a hybrid latent class discrete choice model, which revealed that individuals with different personalities have a willingness to use different transportation modes to the airport [36]. Using the same data for the stated preference choice and the different items, we asked resident air passengers of Tehran about their perceptions of the traffic conditions of the residential built environment, which is available on a different part of that questionnaire used for previous study. This present study's main aim and its unique contribution is to identify the probable association between the effect of air passengers' perceptions of the traffic condition of the built environment and their choice of transportation access mode to IKIA.

Accordingly, we focused on one latent variable, specifically passengers' perception toward built environment (PBE) in their choice of transportation access to the airport.

2.2. Literature Review Regarding Built Environment. Built environment (BE) achieved great interest in previous interdisciplinary studies, particularly regarding transportation. While the effects of BE analyzed various human behaviors, like public health, depressive symptoms, obesity, physical activity, and so on [37-39], BE's effects on transportation planning were primarily evaluated through its consequences on households through vehicle miles or distance traveled, residential selection, and transportation mode choice, in which the majority of the studies indicated that increased population density tended to produce less car use (or fewer vehicle miles traveled) [40-46]. [47] indicated that due to interest in "growing smart" and sustainable forms of urbanization, the study of BEs and their impact on travel behavior will only increase BE's importance over time. Hence, the inclusion of $\mathrm{BE}$ data in transportation mode choice studies was particularly relevant for urban settings [48]. BE factors fell under the domains of density, diversity, and design factors [49]. After controls for sociodemographics and other confounders, design variables tended to have more association with transit and walking choices [50]. Reference [51] concluded that the characteristics of the spatial environment 
seemed to have a demonstrable relationship with mobility and choice of transportation modes. They also mentioned that the reduction in car use is greatest in a densely built-up area [51].

However, $\mathrm{BE}$ has an objective effect on transportation mode choice, and its subjective effects, such as perception and attitudes toward BE, are considered significant. Therefore, attitudes toward travel and land use may be the real determinants of travel distance and residential location [52]. With multivariate analysis of cross-sectional data, [53] showed that people's attitudes largely explain differences in travel behavior between suburban and traditional neighborhoods [53]. Using the nested logit model, [54] indicated that sociodemographic and attitudinal factors played a significant role in vehicle type choice [54]. They also showed that preferences, attitudes, and the $\mathrm{BE}$ itself played prominent roles in explaining variations in nonmotorized travel more than for auto and mass transit trips [55]. In another study, [56] analyzed individuals' environmental attitudes and urban design features' effects on travel patterns and found that individuals' concerns had a strong relationship with walking within and near their neighborhoods but not with cycling or public transport use [56].

Despite efforts to capture the subjective effects of $\mathrm{BE}$, most previous studies used a two-stage approach when considering the perceptional and attitudinal variables of mode choice. Hence, there is a research gap in determining psychometric perceptions toward $\mathrm{BE}$ and their effects on travel mode choice. Therefore, a comprehensive analysis needs to be performed to reveal such effects, especially in employing a simultaneous modeling approach.

\section{Modeling Framework}

Traditional discrete choice models represent the choice process undertaken by individuals facing mutually exclusive alternatives under uncertainty [57]. These approaches make use of observed variables to reveal the behavioral process of decision makers, including sociodemographic information and alternatives' attributes; therefore, such approaches have been criticized by behavioral scientists because they disregard the psychometric aspects of decision makers $[9,58]$. Previous attempts have been made to include attitudes and perceptions of individuals within choice modeling, but these studies set attitudinal variables as explanatory variables within the utility function, which may suffer from measurement errors because the responses of individuals to the statements remained indicators of attitudes or perceptions, rather than a direct measurement of attitudes [59-61].

Recently, a new generation of discrete choice models, such as hybrid choice models (HCMs), has been developed to integrate latent constructs or psychometric variables such as attitude and perception, into the utility function without suffering from measurement error problems or endogeneity bias, which allow researchers to capture psychometric effects of individuals within a choice model [59, 61]. HCMs consist of measurement models that determine the relationship between indicators and psychological factors; HCMs form a structural model that explains the latent constructs with the help of individual characteristics and the discrete choice kernel.

This study investigated the effect of perception toward BE in transportation mode access to the airport. To do so, we constructed settings using an $\mathrm{HCM}$ with three indicators that reflected the perceptions of individuals about ease of access and good traffic conditions within their BE. Next, a latent variable for PBE was defined and entered directly into the utility function of the choice sets (Figure 1).

The upper section of Figure 1 displays a type of structural equation model (SEM) referred to as a multiple indicator and multiple causes (MIMIC) model, which is a confirmatory factor analysis model that relates explanatory variables to the latent construct and uses indicators to reflect PBE. This type of SEM is useful for prediction purposes and represents sociodemographic characteristics of individuals to predict the latent variable. For example, the age of respondents explained differences in PBE. Therefore, the utility of the choice model was a function of the attributes of alternatives and of the explanatory variables related to these alternativesfor example, travel frequency represented in Figure 1-and the latent construct. We adopted the approach presented by Bolduc et al. to model the integration of the latent construct (PBE) within the discrete choice model (in this case, a multinomial logit model). The SEM measurement and structural model are defined in the next section. The functions of the measurement model can be written as [62]

$$
\begin{aligned}
& I=\alpha+\lambda \mathrm{PBE}+v \quad v \sim N(0, \Sigma v) \\
& y_{i}= \begin{cases}1 & \text { if } U_{i}=\max j\left\{U_{j}\right\} \quad i=\text { modes, } \\
0 & \text { otherwise }\end{cases}
\end{aligned}
$$

where

$I$ is vector of 3 indicators of latent construct PBE,

$\alpha$ is vector of unknown parameters that indicated an association between response to scale,

$\lambda$ is vector of unknown parameters that relate latent variables to indicators (loadings),

$v$ is vector of random error terms,

$\Sigma v$ is vector of diagonal matrix with variance of error terms on diagonal, and

$y_{i}$ is choice indicator, taking value 1 if mode $i$ is chosen and 0 otherwise.

The structural model is written below [62] as follows:

$$
\begin{aligned}
\mathrm{PBE} & =X_{1} b+\omega \quad \omega \sim N(0, \Sigma \omega) \\
U & =X_{2} \beta+\gamma \mathrm{PBE}+\varepsilon \quad \varepsilon \sim \text { i.i.d } \operatorname{EV} 1(0,1),
\end{aligned}
$$

where

$X_{1}$ is matrices of explanatory variables,

$X_{2}$ is matrices of attributes of alternatives and explanatory variables, 


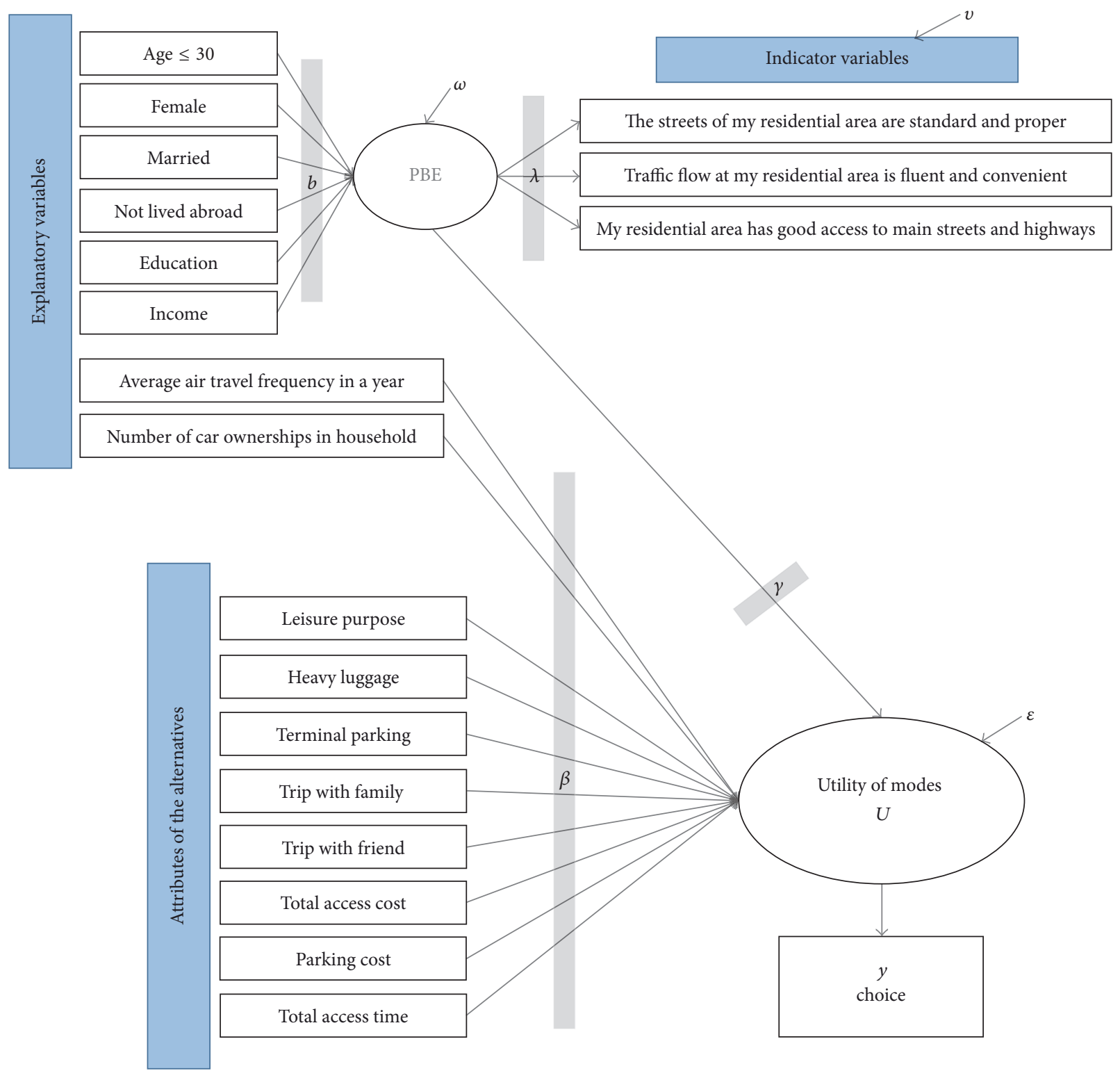

Figure 1: Path diagram of hybrid choice model.

$b$ is vector of unknown parameters used to represent the effect of explanatory variables on the latent construct,

$\omega$ is random disturbance term,

$U$ is vector of utilities,

$\beta$ is vector of unknown parameters used to describe the effect of attributes of alternatives and explanatory variables on modes,

$\gamma$ is vector of an unknown parameter associated with latent variables (here just a latent variable) present in the utility function,

$\varepsilon$ is vector of i.i.d extreme value type 1 error terms, and $\Sigma \omega$ is variance of random disturbance term $\omega$.
The joint probability of choice model with latent variable $\mathrm{PBE}$ and its indicators, which are the joint probability of observing $y_{i}$ and $I$, can be written as follows [62]:

$$
\begin{gathered}
P\left(y_{i}, I \mid X_{1}, X_{2}, \delta\right)=\int_{\mathrm{PBE}} P\left(y_{i} \mid \mathrm{PBE}, X_{2}, \theta\right) \\
\cdot f_{I}(I \mid \mathrm{PBE}, \lambda) f_{\mathrm{PBE}}\left(\mathrm{PBE} \mid X_{1}, b\right) d \mathrm{PBE},
\end{gathered}
$$

where $\theta$ is the all unknown parameters in (3) and $\delta$ is the full set of parameters to estimate $(\delta=\{\theta, \lambda, b\})$. The first term of the integral corresponds to the choice model; the second term corresponds to the measurement equation of the latent construct; and the last term corresponds to the structural equation of the latent construct (PBE). 


\section{Case Study}

4.1. Questionnaire Design. This study used a stated preference (SP) survey questionnaire designed to analyze passengers' behavior regarding accessing Imam Khomeini International Airport (IKIA). In addition, various psychometric questions were used, which related to PBE. Six modes-Drop-off, Park, Van, Taxi, Metro, and Bus-were considered as alternatives, even though metro and bus modes are not currently available. The metro line from Tehran to IKIA is currently under construction. The core element of any SP discrete choice model is choice experiments. The experimental attributes were travel cost (specific for all modes except drop-off); travel time (specific for all modes); three levels for parking facilities (park at terminal parking, park at covered outside of terminal parking areas, and park at outdoor, outside of terminal parking areas); trip purpose; amount of luggage; whether the traveler was making the trip alone, with a friend, or with family; weather conditions; and two facility types for metro and bus. We did not find significant results for weather conditions or facility type. Therefore, these attributes were not included in the utility functions. The levels were combined, and 100 different scenarios based on a D-efficient design were produced in which each respondent faced five scenarios. Therefore, 20 different questionnaires were produced. The attributes and attribute levels for the mode choice experiment are presented in Table 1.

For identification of the latent construct (PBE), we used a MIMIC model where the indicators consisted of three questions reflecting residents' perception of ease of access and good traffic conditions within their residential area. The choices were "(1) I think the streets of my residential area are standard and proper," "(2) I think traffic flow at my residential area is fluent and convenient," and "(3) I think my residential area has good access to main streets and highways." Regarding defining the items, we acknowledge that many previous researchers have conducted environment and transportation studies and fewer studies have considered the perception of the built environment [40, 64-69]. However, we aimed to investigate the residents' perceptions of the association between the traffic conditions of their residential built environments and their choice of transportation mode to the airport. We could not find suitable literature on that topic, as majority of previous studies were not focused on defining items based on capturing the perceptions of the traffic conditions of the built environment. Accordingly, we tried to define the items. Therefore, the items in this present study are new, and they have not been examined in any previous studies. This is part of the contribution of the paper. The items may not be justifiable in terms of what has been investigated in previous studies, but this paper may also open up a new avenue for further studies that exclusively aim to deal with another aspect of the perceptions of the built environment (traffic conditions) rather than previously measured items that evaluated the perceptions of many different subjects of the built environment.

4.2. Data. We conducted a paper-based random systematic survey of passengers departing from Imam Khomeini
TABLE 1: Attributes and attribute levels for mode choice experiment.

\begin{tabular}{|c|c|c|}
\hline Attributes & Number of levels & Levels \\
\hline \multirow{5}{*}{ Travel cost } & \multirow{5}{*}{5} & $\begin{array}{l}\text { Bus: } 5,7,9,11,13 \text { ten } \\
\text { thousand IRR }{ }^{*}\end{array}$ \\
\hline & & $\begin{array}{c}\text { Metro: } 0.5,1,1.5,2,2.5 \\
\text { ten thousand IRR }\end{array}$ \\
\hline & & $\begin{array}{c}\text { Taxi: } 50,55,60,65,70 \\
\text { ten thousand IRR }\end{array}$ \\
\hline & & $\begin{array}{c}\text { Van: } 50,55,60,65,70 \\
\text { ten thousand IRR }\end{array}$ \\
\hline & & $\begin{array}{c}\text { Parking cost: } 5,6,7,9 \text {, } \\
11 \text { ten thousand IRR }\end{array}$ \\
\hline \multirow{6}{*}{ Travel time } & \multirow{6}{*}{7} & $\begin{array}{c}\text { Bus: } 60,70,80,90,100, \\
110,120 \mathrm{~min}\end{array}$ \\
\hline & & $\begin{array}{l}\text { Metro: } 40,50,60,70 \\
80,90,100 \mathrm{~min}\end{array}$ \\
\hline & & $\begin{array}{c}\text { Taxi: } 45,50,55,60,70, \\
\quad 80,90 \mathrm{~min}\end{array}$ \\
\hline & & $\begin{array}{c}\text { Van: } 45,50,55,60,70 \\
80,90 \mathrm{~min}\end{array}$ \\
\hline & & $\begin{array}{c}\text { Park: } 40,50,60,70,80 \\
90,100 \mathrm{~min}\end{array}$ \\
\hline & & $\begin{array}{c}\text { Drop-off: } 40,50,60,70 \\
80,90,100 \mathrm{~min}\end{array}$ \\
\hline Trip Purpose & 2 & Leisure, business \\
\hline Amount of luggage & 2 & Heavy, light \\
\hline Weather conditions & 4 & $\begin{array}{l}\text { Clear, rain, snow, air } \\
\text { pollution }\end{array}$ \\
\hline Trip accompany type & 3 & $\begin{array}{l}\text { Alone, with family, } \\
\text { with others (except } \\
\text { family) }\end{array}$ \\
\hline Parking type & 3 & $\begin{array}{l}\text { Roofed terminal, } \\
\text { roofed outside terminal } \\
\text { (not available now at } \\
\text { IKIA), not roofed } \\
\text { outside terminal }\end{array}$ \\
\hline Metro and bus facilities & 2 & $\begin{array}{l}\text { Luggage check-in and } \\
\text { boarding pass, free } \\
\text { internet access }\end{array}$ \\
\hline
\end{tabular}

*28970 IRR is equal to 1 US dollar (USD) [63].

International Airport (IKIA) during January-February 2015. A total of 641 individuals provided complete responses in which 359 (56\%) of them were residents of the city of Tehran. In order to account for PBE, we separated out the resident respondents from the sample. Table 2 provides an overview of resident sample descriptive statistics, which shows that $27.3 \%$ were under 30 years old, $65.5 \%$ were male, and a similar percentage, $65.5 \%$, of respondents were married. A little over half of the sample had experienced living abroad $(52.4 \%)$ or had a university degree $(56.3 \%)$. More than half of respondents (52.6\%) had a monthly income between 30 and 100 million IRR (IRR (Iranian Rial) is Iran's currency; each US dollar (USD) is equal to 28970 IRR [63]), 30.9\% had less than 30 million IRR, and only $7.8 \%$ had more than 200 million IRR. Almost all residents had a car (95.5\%) and $29.8 \%$ had an average air travel frequency of once or 
TABLE 2: Sample descriptive statistics.

\begin{tabular}{|c|c|c|c|c|c|}
\hline & $N$ & $\%$ & & $N$ & $\%$ \\
\hline Gender & & & Household's monthly income & & \\
\hline Male & 235 & 65.5 & less than 30 million IRR & 111 & 30.9 \\
\hline Female & 124 & 34.5 & 30-100 Million IRR & 189 & 52.7 \\
\hline Age & & & 100-200 Million IRR & 31 & 8.6 \\
\hline Less than 30 & 98 & 27.3 & More than 200 million IRR & 28 & 7.8 \\
\hline 30 and more & 261 & 72.7 & Number of cars in household & & \\
\hline Marital status & & & None & 16 & 4.5 \\
\hline Single & 124 & 34.5 & One & 143 & 39.8 \\
\hline Married & 235 & 65.5 & Two & 142 & 39.6 \\
\hline Lived abroad & & & More than two & 58 & 16.1 \\
\hline Yes & 171 & 47.6 & Trip frequency in a year from IKIA & & \\
\hline No & 188 & 52.4 & Once or less & 107 & 29.8 \\
\hline Education & & & Two times & 93 & 25.9 \\
\hline Not university & 157 & 43.7 & Three times & 74 & 20.6 \\
\hline University degree & 202 & 56.3 & More than three times & 85 & 23.7 \\
\hline Current mode & & & Trip purpose & & \\
\hline Roofed terminal parking & 67 & 18.7 & Business & 115 & 32 \\
\hline Outside terminal parking & 42 & 11.7 & Leisure & 133 & 37 \\
\hline Drop-off & 54 & 15 & Educational & 38 & 10.6 \\
\hline Taxi & 184 & 51.3 & Others & 73 & 20.4 \\
\hline Van & 12 & 3.3 & Amount of luggage & & \\
\hline Trip origin & & & One piece & 26 & 7.2 \\
\hline Home & 350 & 97.5 & Two pieces & 206 & 57.4 \\
\hline Office & 8 & 2.2 & Three pieces & 96 & 26.7 \\
\hline City business centers & 1 & 0.3 & More than three pieces & 31 & 8.7 \\
\hline
\end{tabular}

less from IKIA, followed by two times (25.9\%), three times $(20.6 \%)$, and more than three times $(23.7 \%)$. The majority of respondents started their trip to the airport from home (97.5\%), followed by respondents who left from the office $(2.2 \%)$. More than half of respondents indicated that they accessed the airport by taxi $(51.3 \%)$, while $30.4 \%$ parked at airport parking areas, 15\% were dropped off, and only $3.3 \%$ used a van service. Leisure was reported by most passengers as the purpose of travel by resident respondents (37\%), followed by business purpose (32\%), educational purpose $(10.6 \%)$, or other purposes $(20.4 \%)$. The respondents were asked to indicate their amount of luggage; most of them had two pieces (57.4\%), followed by three pieces (26.7\%) and more than three pieces $(8.7 \%)$, and only $7.2 \%$ had one piece of luggage.

The responses regarding indicators of PBE are reported in Table 3. Three questions were asked of respondents, which reflected their perception of the ease of access and good traffic conditions within their BE. The responses to these three questions were ranged upon a five-point Likert scale: "Strongly Disagree," "Disagree," "Neither Disagree nor Agree," "Agree," and "Strongly Agree."

For determining whether the sample is the representative sample of resident population of Tehran or not, it must be noted that according to the statistics available for the city of Tehran, the mean age of the population in that city is 31.2 years [70], which is slightly different from the mean age of the study's sample, which is 39.1 years (359 individuals completed the questionnaire). Moreover, the mean average income for households in Tehran is 27 million IRR, which is different from our sample, where most of the respondents $(52.7 \%)$ indicated that their monthly household income ranged from 30 to 100 million IRR [71]. This difference may be attributed to the fact that Imam Khomeini International Airport (IKIA) only serves international flights, and international air passengers may have more income than average residents of Tehran because international air passengers go on international business or leisure trips. The average population of Tehran might not be able to take these kinds of trips, especially in a developing country such as Iran, in which a high difference in socioeconomic status (SES) may exists among residents.

Additionally, based on the census reports conducted in November 2011, 4,130,915 of the 8,293,140 residents of Tehran were male (49.81\%) and 4,162,225 were female (50.19\%) [72]. Thus, there were differences between the study sample and the population of Tehran; $65.5 \%$ of the study sample was male and $34.5 \%$ was female. This may be attributed to the following reasons. First, only people older than 17 were selected to answer the study questions because individuals younger than 17 might not answer the questions correctly. They are also more dependent on their parents or other people for transportation to the airport and so they can take an international flight. Moreover, we could not identify a gender ratio for the population older than 17 from information provided by 
TABLE 3: Descriptive statistics of indicators.

(a)

\begin{tabular}{lcc}
\hline Question & Mean & Stdv \\
\hline (1) I think the streets of my residential area are standard and proper & 1.49 & 1.24 \\
(2) I think traffic flow at my residential area is fluent and convenient & 1.42 & 1.13 \\
(3) I think my residential area has good access to main streets and highways & 2.63 & 1.11 \\
\hline
\end{tabular}

(b)

\begin{tabular}{lcccccc}
\hline Question & Strongly Disagree $\%$ & Disagree $\%$ & Neither Disagree nor Agree $\%$ & Agree\% & Strongly Agree $\%$ & Total $N$ \\
\hline Q1. & 25.3 & 33.2 & 15 & 20.1 & 6.4 & 359 \\
Q2. & 23.5 & 37 & 15 & 22.8 & 1.7 & 359 \\
Q3. & 6.1 & 12.8 & 12 & 50.4 & 18.7 & 359 \\
\hline
\end{tabular}

IKIA authorities and the transportation agencies in Iran. Second, as mentioned before, IKIA only serves international flights; therefore, the gender ratio of the resident population of Tehran who take international flights may be different from the total population of that city.

Accordingly, we tried to find a relevant study that examined resident air passengers at IKIA. We were only able to find a study that was conducted on air passengers at Tehran airports (IKIA and Mehrabad International Airport [MIA]) [73]. In that study, 1242 of the 2757 respondents who used these two airports were residents (45\%) of Tehran [73], which is $11 \%$ less than our study (56\% of the respondents in our study were residents of Tehran). However, that study's report about the share of resident air passengers is based on the total sample gathered from both IKIA and MIA, and the population of MIA air passengers may be different from the population of IKIA air passengers. Owing to the lack of data and due to the limitations of information available in Iran, we could not find valid data regarding the resident population of Tehran who make use of IKIA from the IKIA authority and transportation agencies in Iran. Therefore, based on the above-mentioned statements, our sample seems to be the only available representative sample of resident air passengers that use IKIA. This could be a limitation of our study, and the study's findings cannot be generalized to the behavior of the resident population of Tehran. Consequently, the study's results may be limited to residents of Tehran who only use IKIA.

\section{Model Specification and Estimation Results}

5.1. Model Specification. As presented in Section 3, Modeling Framework, the HCM framework that we adopted, consists of two main components: a MIMIC model and a discrete choice model. This framework described how individuals' perceptions toward BE can affect transportation mode choice to the airport [59]. The MIMIC model consisted of measurement and structural relationships. The measurement equations related a latent variable (PBE) to its indicators (three perceptional questions), but the structural equations explained the latent variable $(\mathrm{PBE})$ with exogenous explanatory variables. There was another structural equation in the HCM, linking the attributes of alternatives, explanatory variables, and the latent variable to the utility function of the transportation modes. In this section, we continue the illustration of each part of the model's equations.

The six alternatives were considered in the choice setDrop-off, Park, Van, Taxi, Metro, and Bus-where metro and the bus are not currently available. Each individual was faced with five different SP scenarios. Therefore, of the 359 resident responses, there were 1795 SP observations. Taxi was chosen 710 times (39.55\%), followed by metro 405 times $(22.55 \%)$, park 265 times (14.8\%), van 195 times (10.85\%), drop-off 175 times $(9.75 \%)$, and bus 45 times $(2.5 \%)$.

The deterministic part of the utility function for mode choice consisted of attributes and, in our case, two explanatory variables "average air travel frequency in a year" and "number of car ownerships in the household." The experimental attributes of alternatives were "travel cost," "travel time," "trip purpose," "amount of luggage," "trip accompany type," and "parking type." We estimated many different models, but we did not find any significant results regarding weather conditions or metro/bus facilities. Therefore, these attributes were not included in the utility function. We also included the interaction of the number of cars in a household variable and the latent variable or PBE within the utility function for the van, taxi, metro, and bus choices but included $\mathrm{PBE}$ in the utility function of the park alternative without considering the interaction. Also, the alternative specific constants (ASCs) were included in all the utility functions of mode choice except for parking mode. The equations of discrete choice utility functions are presented below as follows:

$$
\begin{aligned}
U_{\text {drop-off }}= & \beta_{\text {drop-off }}+\varepsilon_{\text {drop-off }} \\
U_{\text {park }}= & \beta_{\text {freq } p} \text { Freq }+\beta_{\text {heavy } p} \text { Heavy } \\
& +\beta_{\text {liesure } p} \text { Liesure }+\beta_{\text {family } p} \text { Family } \\
& +\beta_{\text {cost } p}\left(\frac{\text { Cost } P}{\text { Income }}\right) \\
& +\beta_{\text {terminal } p} \text { Terminal } P+\beta_{\mathrm{PBE} p} \text { PBE } \\
& +\varepsilon_{\text {park }}
\end{aligned}
$$




$$
\begin{aligned}
& U_{\text {van }}=\beta_{\text {van }}+\beta_{\text {freq } v} \text { Freq }+\beta_{\text {heavy } v} \text { Heavy } \\
& +\beta_{\text {friend } v} \text { Friend }+\beta_{\text {family } v} \text { Family } \\
& +\beta_{\text {cost } v}\left(\frac{\text { Cost } V}{\text { Income }}\right)+\beta_{\text {time } v} \text { Time } V \\
& +\beta_{\mathrm{PBE} v} \mathrm{NCH} \times \mathrm{PBE}+\varepsilon_{\mathrm{van}} \\
& U_{\text {taxi }}=\beta_{\text {taxi }}+\beta_{\text {freq } t} \text { Freq }+\beta_{\text {cost } t}\left(\frac{\operatorname{Cost} T}{\text { Income }}\right) \\
& +\beta_{\text {time } t} \text { Time } T+\beta_{\mathrm{PBE} t} \mathrm{NCH} \times \mathrm{PBE} \\
& +\varepsilon_{\text {taxi }} \\
& U_{\text {metro }}=\beta_{\text {metro }}+\beta_{\text {freq } m} \text { Freq }+\beta_{\text {heavy } m} \text { Heavy } \\
& +\beta_{\text {family } m} \text { Family }+\beta_{\text {cost } m} \operatorname{Cost} M \\
& +\beta_{\text {time } m} \text { Time } M+\beta_{\mathrm{PBE} m} \mathrm{NCH} \times \mathrm{PBE} \\
& +\varepsilon_{\text {metro }} \\
& U_{\text {bus }}=\beta_{\text {bus }}+\beta_{\text {heavy } b} \text { Heavy }+\beta_{\text {liesure } b} \text { Liesure } \\
& +\beta_{\text {cost } b} \operatorname{Cost} B+\beta_{\text {time } b} \text { Time } B \\
& +\beta_{\mathrm{PBE} b} \mathrm{NCH} \times \mathrm{PBE}+\varepsilon_{\text {bus }},
\end{aligned}
$$

where

Freq is average air trip from IKIA in a year by individuals,

Heavy is amount of luggage ( 1 for heavy luggage, 0 otherwise),

Leisure is trip purpose ( 1 for leisure purpose, 0 otherwise),

Friend is trip accompany type ( 1 for make trip with friend, 0 otherwise),

Family is trip accompany type (1 for make trip with family, 0 otherwise),

Terminal $P$ is type of parking area ( 1 for terminal roofed parking area, 0 otherwise),

Cost $P$ is cost of parking area per day (ten thousand IRR),

Cost $V$ is travel cost by van (ten thousand IRR),

Cost $T$ is travel cost by taxi (ten thousand IRR),

Cost $M$ is travel cost by metro (ten thousand IRR),

Cost $B$ is travel cost by bus (ten thousand IRR),

Time $V$ is travel time by van ( $\mathrm{min}$ ),

Time $T$ is travel time by taxi ( $\mathrm{min})$,

Time $M$ is travel time by metro ( $\mathrm{min}$ ),

Time $B$ is travel time by bus ( $\mathrm{min}$ ),

Income is household's monthly income (ten million IRR)
$\mathrm{NCH}$ is number of cars in household,

$\mathrm{PBE}$ is latent variable regarding perception toward built environment, and

$\varepsilon_{\text {drop-off }}, \varepsilon_{\text {park }}, \varepsilon_{\text {van }}, \varepsilon_{\text {taxi }}, \varepsilon_{\text {metro }}, \varepsilon_{\text {bus }}$ are error terms relative to the utility function of each mode.

The measurement equations which use the values of perceptional questions (indicators) as dependent variable to reflect latent variable PBE can be written as shown below.

$$
\begin{aligned}
& I_{1}=\alpha_{1}+\lambda_{1} \mathrm{PBE}+v_{1} \\
& I_{2}=\alpha_{2}+\lambda_{2} \mathrm{PBE}+v_{2} \\
& I_{3}=\alpha_{3}+\lambda_{3} \mathrm{PBE}+v_{3},
\end{aligned}
$$

where:

$I_{1}, I_{2}, I_{3}$ are indicators relative to perceptional questions 1 to 3 ,

$\alpha_{1}, \alpha_{2}, \alpha_{3}$ are unknown parameters that indicate association between response to scale ( $\alpha_{1}$ is set to 0 for normalization),

$\lambda_{1}, \lambda_{2}, \lambda_{3}$ are unknown parameters that relate latent variable $\mathrm{PBE}$ to the indicators $\left(\lambda_{1}\right.$ is set to 1 for normalization), and

$v_{1}, v_{2}, v_{3}$ are random error terms.

The structural equation in the MIMIC model explains differences in latent variable PBE with exogenous explanatory variables by linear relations. The present model uses explanatory variables age, gender, marital status, experience in living abroad, education, and income to identify variation in PBE. The equation is given bellow.

$$
\begin{aligned}
\mathrm{PBE}= & b_{\mathrm{PBE}}+b_{\text {age }} \text { Age } \\
\leq & 30+b_{\text {female }} \text { Female }+b_{\text {married }} \text { Married } \\
& +b_{\text {livingexp }} \text { LivingExp }+b_{\text {edu }} \text { Edu } \\
< & \text { University }+b_{\text {income }} \text { Income }<3+\omega_{\mathrm{PBE}},
\end{aligned}
$$

where:

Age $\leq 30$ is age ( 1 for having age equal or less than 30 years old, 0 otherwise),

Female is gender (1 for female, 0 otherwise),

Married is marital status ( 1 for married, 0 otherwise),

LivingExp is experience in living abroad ( 1 for no experience in living abroad, 0 otherwise),

Edu < University is education (1 for less than university degree, 0 otherwise),

Income $<3$ is household's monthly income (1 for monthly income less than 30 million IRR, 0 otherwise), and

$\omega_{\mathrm{PBE}}=$ random error term. 
5.2. Model Estimation Results. The results of transportation mode choice for airport access are presented in Table 4. For calculation of the hybrid choice model which is the simultaneous combination of SEM and discrete choice model, we used PythonBiogeme software package which was developed by Bierlaire [74]. All estimated travel time and cost parameters are in the expected signs. However, travel time parameters for the van, taxi, and metro were not significant. The results showed that more frequent air travelers are inclined to use the van, taxi, metro, and park at the airport modes. In addition, more frequent travelers had an increased tendency to park at the terminal's covered parking area, while leisure travelers were more inclined to park at the airport or use the bus. A large amount of luggage had a significant positive effect on parking at the airport or using a van service, with a negative impact on the tendency to choose the metro or bus. Being accompanied for the trip had a significant effect on transportation access to the IKIA. Being with family on a trip increased the tendency to park at the airport or to use a van service, while it decreased willingness to use the metro. In addition, making a trip with friends resulted in an increased tendency to choose a van service.

For inclusion of the latent variable PBE, as previously mentioned, we considered the interaction of PBE with the number of cars in the household for the van, taxi, bus, and metro modes as an additive term for inclusion in the utility of parking at the airport. A more positive perception of $\mathrm{BE}$ (better traffic conditions and ease of access to main streets and highways) was in line with increased willingness to park at the airport. In addition, the interaction of the latent variable with the number of cars in households had a negative effect in choosing other transportation modes, with a particularly increased negative effect on the metro and bus choices.

Table 5 shows the results of the structural and measurement equations. The structural equations revealed that younger passengers, or those less than or equal to 30 years old, had a more positive perception toward their BE than older people. Females and passengers who were married, rather than males or singles, perceived that their built environment was in good condition. In addition, less-educated (less than a university degree) and lower-income passengers (monthly income less than 3 million IRR) perceived their BE more positively, while the most significant explanatory variable in determining PBE was experience in living abroad, where those who had not experienced living abroad had more positive PBE.

In the calibration process, we tried to calibrate many models to identify the best model based on the fit criteria of the overall HCM and the significance of the estimated parameters. Therefore, we were able to determine that age, gender, marital status, condition of experience living abroad, educational level, and income had a 10\% significance level. Hence, we kept these variables.

Table 6 depicts the calculation of direct elasticity and cross-elasticity of travel time and travel costs. Direct elasticity represented the average percentage change in the probability output of an alternative, with a response to a $1 \%$ change in the value of the variable (attribute) of that alternative. Meanwhile, the cross-elasticity is the amount of change in the choice
TABLE 4: HCM model estimation results, mode choice model.

\begin{tabular}{lcccc}
\hline Parameter & Estimate & Std err & $t$-stat & $p$ value \\
\hline$\beta_{\text {drop-off }}$ & 0.481 & 0.283 & 1.70 & 0.09 \\
$\beta_{\text {van }}$ & 0.422 & 0.490 & 0.86 & 0.39 \\
$\beta_{\text {taxi }}$ & 2.58 & 0.321 & 8.02 & 0.00 \\
$\beta_{\text {metro }}$ & 2.22 & 0.371 & 5.99 & 0.00 \\
$\beta_{\text {bus }}$ & 2.04 & 1.06 & 1.93 & 0.05 \\
Parking cost/income, park & -0.189 & 0.0435 & -4.34 & 0.00 \\
Leisure, park & 0.278 & 0.146 & 1.90 & 0.06 \\
Heavy, park & 0.348 & 0.150 & 2.32 & 0.02 \\
With family, park & 0.390 & 0.157 & 2.47 & 0.01 \\
Terminal roofed parking, park & 0.352 & 0.144 & 2.44 & 0.01 \\
Frequency, park & 0.129 & 0.0357 & 3.61 & 0.00 \\
Travel cost/income, van & -0.0165 & 0.0059 & -2.80 & 0.01 \\
Travel time, van & -0.00841 & 0.00524 & -1.60 & 0.11 \\
Heavy, van & 0.912 & 0.171 & 5.32 & 0.00 \\
With friend, van & 0.739 & 0.221 & 3.34 & 0.00 \\
With family, van & 0.601 & 0.246 & 2.44 & 0.01 \\
Frequency, van & -10494.9 & & & \\
Travel cost/income, taxi & 0.494 & & & \\
Travel time, taxi & -0.0153 & 0.0036 & -4.24 & 0.00 \\
Frequency, taxi & -0.0016 & 0.0033 & -0.48 & 0.63 \\
Travel cost, metro & 0.081 & 0.0346 & 2.34 & 0.02 \\
Travel time, metro & -0.0942 & 0.0985 & -0.96 & 0.34 \\
Heavy, metro & -0.004 & 0.003 & -1.33 & 0.18 \\
Family, metro & -1.09 & 0.146 & -7.46 & 0.00 \\
Frequency, metro & -0.675 & 0.169 & -4.00 & 0.00 \\
Travel cost, bus & 0.0936 & 0.0363 & 2.58 & 0.01 \\
Travel time, bus & -0.135 & 0.0661 & -2.05 & 0.04 \\
Leisure, bus & -0.0217 & 0.0107 & -2.02 & 0.04 \\
Heavy, bus & 0.850 & 0.383 & 2.22 & 0.03 \\
PBE, park & -0.967 & 0.406 & -2.38 & 0.02 \\
NCH $\times$ PBE, van & 0.173 & 0.101 & 1.72 & 0.09 \\
NCH $\times$ PBE, taxi & -0.0829 & 0.0406 & -2.04 & 0.04 \\
NCH $\times$ PBE, metro & -0.120 & 0.0294 & -4.09 & 0.00 \\
NCH $\times$ PBE, bus & 0.0375 & -3.36 & 0.00 \\
\hline Observations & 0.0968 & -1.33 & 0.18 \\
Respondents & & & \\
HCM parameters & -20730.5 & & & \\
\hline
\end{tabular}

probability output of an alternative with response to a $1 \%$ change in the value of an attribute of another alternative [7577]. One important property of multinomial logit models (MNL) is the existence of the same cross-elasticities for all the other alternatives in the choice set, which is due to the independence from irrelevant alternatives (IIA) property of MNL [75-77]. The direct elasticity results show that travel time and travel costs are only elastic for the bus transport mode (values of elasticity analysis for them is greater than 
TABLE 5: HCM model estimation results, structural and measurement equations (MIMIC parts).

\begin{tabular}{lcccc}
\hline Parameter & Estimate & Std err & $t$-Stat & $p$ Value \\
\hline Structural equations & & & & \\
\hline$b_{\text {PBE }}$ & 0.917 & 0.0671 & 13.66 & 0.00 \\
Age $\leq 30$ & 0.36 & 0.630 & 5.71 & 0.00 \\
Female & 0.111 & 0.0588 & 1.89 & 0.06 \\
Married & 0.230 & 0.0574 & 4.01 & 0.00 \\
Not lived abroad & 0.442 & 0.0558 & 7.92 & 0.00 \\
Education < university & 0.138 & 0.0786 & 1.75 & 0.08 \\
Income $<3$ million IRR & 0.117 & 0.0592 & 1.97 & 0.05 \\
$\sigma_{\omega}$ & 0.906 & 0.0410 & 22.12 & 0.00 \\
\hline Measurement equations & & & & \\
\hline$\alpha_{1}$ & 0 & N.A & N.A & N.A \\
$\alpha_{2}$ & 0.194 & 0.0958 & 2.03 & 0.04 \\
$\alpha_{3}$ & 2.11 & 0.0577 & 36.60 & 0.00 \\
$\lambda_{1}$ & 1 & N.A & N.A & N.A \\
$\lambda_{2}$ & 0.825 & 0.0622 & 13.25 & 0.00 \\
$\lambda_{3}$ & 0.346 & 0.0346 & 10.00 & 0.00 \\
$\sigma_{v 1}$ & 0.793 & 0.0433 & 18.33 & 0.00 \\
$\sigma_{v 2}$ & 0.804 & 0.0310 & 25.99 & 0.00 \\
$\sigma_{v 3}$ & 1.06 & 0.0184 & 57.62 & 0.00 \\
\hline & & & &
\end{tabular}

TABLE 6: Elasticity analysis of travel time and travel cost (values in $\%)$.

\begin{tabular}{|c|c|c|c|}
\hline Modes & & $\begin{array}{l}\text { Travel } \\
\text { time }\end{array}$ & $\begin{array}{c}\text { Travel cost or travel } \\
\text { cost/income }\end{array}$ \\
\hline \multicolumn{4}{|c|}{ Direct-elasticities } \\
\hline Park & & N.A & -0.380 \\
\hline Van & & -0.484 & -0.258 \\
\hline Taxi & & -0.055 & -0.152 \\
\hline Metro & & -0.232 & -0.114 \\
\hline Bus & & -1.836 & -1.186 \\
\hline \multicolumn{4}{|c|}{ Cross-elasticities } \\
\hline Park & \multirow{5}{*}{$\begin{array}{l}\text { On probability } \\
\text { of other } \\
\text { transport } \\
\text { modes }\end{array}$} & N.A & 0.047 \\
\hline Van & & 0.057 & 0.030 \\
\hline Taxi & & 0.046 & 0.120 \\
\hline Metro & & 0.052 & 0.024 \\
\hline Bus & & 0.032 & 0.019 \\
\hline
\end{tabular}

1), which represents that with a $1 \%$ increase in the amount of travel time or travel cost of bus alternatives, the probability of choosing bus service decreases more than $1 \%$.

Analysis of the behavior of resident air passengers in Tehran also revealed that they are less sensitive to the travel time of taxis and the travel costs of the metro, which may be due to the relatively low travel costs of the metro in comparison to other modes of transport in Iran, and the confidence interval of travel time they consider when using taxis. Based on the information presented in Table 4, it must be noted that travel costs for the metro and the travel time estimated for vans, taxis, and the metro were not statistically significant, which might be attributed to resident air passengers considering free time before a flight for access to the airport, and they may have a relatively higher income than other passengers as they are able to take international flights (IKIA only serves international flights). In addition, we compared our results to the findings of previous studies of elasticity analysis; however, such elasticity analysis does not exist, particularly in the context of ground access to the airports' literature review. As the HCM methodology is relatively new, almost all significant scholarly papers which used hybrid choice methods did not report elasticities [7, 8, $10,61,62,78-85]$.

\section{Discussion and Conclusions}

This paper investigated the influence of travelers' perceptions toward $\mathrm{BE}$ in airport access transportation modes. For this purpose, we used SP data gathered from departure resident air passengers at Imam Khomeini International Airport during January and February 2015. With 359 validated responses and a total of 1795 SP observations, a hybrid choice model was implemented to capture the effect of the latent variable within the choice process.

The discrete choice model results indicated that with the introduction of the metro alternative, the metro option could catch a high share of passengers at $22.55 \%$. However, the bus option captured only $2.5 \%$ of travelers, similar to results presented for the Port Columbus International Airport bus system, where only $2.35 \%$ of respondents had interest in using the bus; therefore, the bus option would not attain much of a share [20]. Moreover, in line with the study of Taoyuan International Airport, which indicated that convenience in storing and retrieving luggage was one of three primary concerns of air travelers [24], policymakers must focus on finding a better solution for more convenient luggage storage within the metro to increase its potential share in accessing IKIA. Additionally, traveler accompaniment type had a significant effect on passenger's airport travel mode choice to IKIA, in which those who were traveling with friends had an increased tendency to choose van transport, while those who traveled with their families showed an increased willingness to park at the airport or use a van service.

The result of the effect of the latent variable (PBE) on transportation access mode choice showed that a more positive PBE led to more willingness to use a private car and park at the airport. These findings were in line with previous studies of BE's objective effect, which indicated that living in denser population areas reduced private car use, while living in a less dense population area or a suburban location increased private car use $[44,46,53]$. Additionally, the interaction of the number of cars in the household and PBE had significant negative effects in the willingness to choose van, taxi, and metro modes of transportation, with the most negative impact on choosing the metro. Because more than half of the sample data $(56 \%$, or 359 out of 641 responses) were Tehran residents, the more positive perception of resident air passengers toward their BE led to an increased tendency to park at the airport. This tendency 
may cause more problems for the near-airport environment such as air and noise pollution.

The MIMIC model showed that sociodemographic characteristics of individuals can explain the variation in PBE. Younger passengers, females, married people, less-educated persons, and low-income individuals had higher values of PBE. In addition, experience living in a foreign country was noteworthy in explaining differences of PBE and showed that inexperienced individuals had an overall more positive PBE. However, this data also showed an opportunity for policymakers; people's perceptions regarding BE were on the side of more public transport; therefore, increased mass transit options could affect the behavior of transportation users toward less private car use. Targeting policy toward lesseducated persons and younger passengers and introducing $\mathrm{BE}$ similar to that of other countries could improve future transport outcomes, particularly within developing countries such as Iran.

Regarding the limitation of the study, the sample may not be the representative of the resident of Tehran and the results of this study might not be generalizable to the behavior of resident of Tehran but only to those resident air passengers making international flights at IKIA. Therefore, whether domestic flights become available at IKIA or not will need further research. Moreover, The SEM fit criteria within HCM must be calculated and reported which required further research [86].

For future studies, the mismatch effect of perception toward existing $\mathrm{BE}$ and the objective $\mathrm{BE}$ must be taken into account. In addition, perceptions toward both the airport environment as a destination and the parking environment could benefit from a more detailed investigation, specifically regarding travel behavior in accessing the airport. Other perceptional and attitudinal aspects, including BE's effects on the habit of car use, ecological behaviors, and personality traits, should be considered in the access design of airports. Moreover, we suggest that future studies develop a method to analyze the existence of a covariance term between error terms and find a way to calculate the modification fit indices of the SEM portion of the hybrid choice model, which can strengthen the fit of the model to the sample data. It is also recommended to analyze the effect of $\mathrm{PBE}$ and other latent construct specially personality traits as previously reported that have significant effect on access mode choice to airport [36].

\section{Competing Interests}

The authors declare that there are no competing interests regarding the publication of this paper.

\section{References}

[1] V. Van Acker, B. Derudder, and F. Witlox, "Why people use their cars while the built environment imposes cycling," Journal of Transport and Land Use, vol. 6, no. 1, pp. 53-62, 2013.

[2] P. L. Mokhtarian and X. Cao, "Examining the impacts of residential self-selection on travel behavior: a focus on methodologies," Transportation Research Part B: Methodological, vol. 42, no. 3, pp. 204-228, 2008.
[3] V. van Acker, B. van Wee, and F. Witlox, "When transport geography meets social psychology: toward a conceptual model of travel behaviour," Transport Reviews, vol. 30, no. 2, pp. 219240, 2010.

[4] M. N. Bagley and P. L. Mokhtarian, "The impact of residential neighborhood type on travel behavior: a structural equations modeling approach," The Annals of Regional Science, vol. 36, no. 2, pp. 279-297, 2002.

[5] J. Scheiner and C. Holz-Rau, "Travel mode choice: affected by objective or subjective determinants?” Transportation, vol. 34, no. 4, pp. 487-511, 2007.

[6] E. Heinen, K. Maat, and B. Van Wee, "The role of attitudes toward characteristics of bicycle commuting on the choice to cycle to work over various distances," Transportation Research Part D: Transport and Environment, vol. 16, no. 2, pp. 102-109, 2011.

[7] M. Kamargianni, S. Dubey, A. Polydoropoulou, and C. Bhat, "Investigating the subjective and objective factors influencing teenagers' school travel mode choice-an integrated choice and latent variable model," Transportation Research Part A: Policy and Practice, vol. 78, pp. 473-488, 2015.

[8] M. Kamargianni and A. Polydoropoulou, "Hybrid choice model to investigate effects of teenagers' attitudes toward walking and cycling on mode choice behavior," Transportation Research Record, no. 2382, pp. 151-161, 2013.

[9] R. Maldonado-Hinarejos, A. Sivakumar, and J. W. Polak, "Exploring the role of individual attitudes and perceptions in predicting the demand for cycling: a hybrid choice modelling approach," Transportation, vol. 41, no. 6, pp. 1287-1304, 2014.

[10] Y. Motoaki and R. A. Daziano, "A hybrid-choice latent-class model for the analysis of the effects of weather on cycling demand," Transportation Research Part A: Policy and Practice, vol. 75, pp. 217-230, 2015.

[11] IKIA, "Transportation to IKIA, Imam Khomeini International Airport, Persian Version,” 2015, http://ikia.airport.ir/office/ pages/trans.

[12] Anna Aero, 2015, http://www.anna.aero/2015/02/27/tehranairport-reports-23-capacity-growth-in-10-years/.

[13] Tehran Metro Group Official Site, "Tehran Metro Line in 2030," 2015, http://tehranmetrogroup.com/index.aspx?siteid=1\&fkeyid= \&siteid=1\&pageid $=763$.

[14] Iran national Statistics portal, 2013, http://www.amar.org.ir/ Default.aspx?tabid $=667 \&$ fid $=6897$.

[15] City Mayors Statistics, 2007, http://www.citymayors.com/statistics/largest-cities-density-125.html.

[16] Tehran Municipality portal, 2015, http://en.tehran.ir/Default .aspx?tabid=97.

[17] A. Madanipour, "City profile: Tehran," Cities, vol. 16, no. 1, pp. $57-65,1999$.

[18] F. Atash, "The deterioration of urban environments in developing countries: mitigating the air pollution crisis in Tehran, Iran," Cities, vol. 24, no. 6, pp. 399-409, 2007.

[19] M. Seifollahi and S. Faryadi, "Evaluating the quality of Tehran's urban environment based on sustainability indicators," International Journal of Environmental Research, vol. 5, no. 2, pp. 545$554,2011$.

[20] G. Akar, "Ground access to airports, case study: Port Columbus International Airport," Journal of Air Transport Management, vol. 30, pp. 25-31, 2013.

[21] P. Koster, E. Kroes, and E. Verhoef, "Travel time variability and airport accessibility," Transportation Research Part B: Methodological, vol. 45, no. 10, pp. 1545-1559, 2011. 
[22] S. N. Alhussein, "Analysis of ground access modes choice King Khaled International Airport, Riyadh, Saudi Arabia," Journal of Transport Geography, vol. 19, no. 6, pp. 1361-1367, 2011.

[23] G. Harvey, "Study of airport access mode choice," Journal of Transportation Engineering, vol. 112, no. 5, pp. 525-545, 1986.

[24] R.-C. Jou, D. A. Hensher, and T.-L. Hsu, "Airport ground access mode choice behavior after the introduction of a new mode: A case study of Taoyuan International Airport in Taiwan," Transportation Research Part E: Logistics and Transportation Review, vol. 47, no. 3, pp. 371-381, 2011.

[25] G. Başar and C. Bhat, "A parameterized consideration set model for airport choice: an application to the San Francisco Bay Area," Transportation Research Part B: Methodological, vol. 38, no. 10, pp. 889-904, 2004.

[26] S. Carstens, "Domestic airport passenger access mode choice decisions in a multi-airport region of South Africa," Journal of Transport and Supply Chain Management, vol. 8, no. 1, 7 pages, 2014.

[27] S. Hess and J. W. Polak, "Mixed logit modelling of airport choice in multi-airport regions," Journal of Air Transport Management, vol. 11, no. 2, pp. 59-68, 2005.

[28] E. Pels, P. Nijkamp, and P. Rietveld, "Access to and competition between airports: a case study for the San Francisco Bay area," Transportation Research Part A: Policy and Practice, vol. 37, no. 1, pp. 71-83, 2003.

[29] V. Psaraki and C. Abacoumkin, "Access mode choice for relocated airports: the new athens International Airport," Journal of Air Transport Management, vol. 8, no. 2, pp. 89-98, 2002.

[30] P. R. Rassam, R. H. Ellis, and J. C. Bennett, The N-Dimensional Logit Model: Development and Application, Peat, Marwick, Mitchell \& Co, London, UK, 1970.

[31] M. L. Tam, W. H. K. Lam, and H. P. Lo, "Modeling air passenger travel behavior on airport ground access mode choices," Transportmetrica, vol. 4, no. 2, pp. 135-153, 2008.

[32] D. Tsamboulas, A. P. Evmorfopoulos, and P. Moraiti, "Modeling airport employees commuting mode choice," Journal of Air Transport Management, vol. 18, no. 1, pp. 74-77, 2012.

[33] D. A. Tsamboulas and A. Nikoleris, "Passengers' willingness to pay for airport ground access time savings," Transportation Research Part A: Policy and Practice, vol. 42, no. 10, pp. 12741282, 2008.

[34] Y.-C. Chang, "Factors affecting airport access mode choice for elderly air passengers," Transportation Research Part E: Logistics and Transportation Review, vol. 57, pp. 105-112, 2013.

[35] T. Budd, T. Ryley, and S. Ison, "Airport ground access and private car use: a segmentation analysis," Journal of Transport Geography, vol. 36, pp. 106-115, 2014.

[36] M. Yazdanpanah and M. H. Hosseinlou, "The influence of personality traits on airport public transport access mode choice. A hybrid latent class choice modeling approach," Journal of Air Transport Management, vol. 55, pp. 147-163, 2016.

[37] H. M. Badland, M. Oliver, R. A. Kearns et al., "Association of neighbourhood residence and preferences with the built environment, work-related travel behaviours, and health implications for employed adults: findings from the URBAN study," Social Science \& Medicine, vol. 75, no. 8, pp. 1469-1476, 2012.

[38] D. T. Duncan, G. Piras, E. C. Dunn, R. M. Johnson, S. J. Melly, and B. E. Molnar, "The built environment and depressive symptoms among urban youth: a spatial regression study," Spatial and Spatio-temporal Epidemiology, vol. 5, no. 1, pp. 1125, 2013.
[39] Y. Xu and F. Wang, "Built environment and obesity by urbanicity in the U.S.", Health \& Place, vol. 34, pp. 19-29, 2015.

[40] C. R. Bhat and J. Y. Guo, "A comprehensive analysis of built environment characteristics on household residential choice and auto ownership levels," Transportation Research Part B: Methodological, vol. 41, no. 5, pp. 506-526, 2007.

[41] A. Broberg and S. Sarjala, "School travel mode choice and the characteristics of the urban built environment: the case of Helsinki, Finland," Transport Policy, vol. 37, pp. 1-10, 2015.

[42] R. Cervero and J. Murakami, "Effects of built environments on vehicle miles traveled. Evidence from 370 US urbanized areas," Environment and Planning A, vol. 42, no. 2, pp. 400-418, 2010.

[43] C. Chen, H. Gong, and R. Paaswell, "Role of the built environment on mode choice decisions: additional evidence on the impact of density," Transportation, vol. 35, no. 3, pp. 285-299, 2008.

[44] J.-S. Lee, J. Nam, and S.-S. Lee, "Built environment impacts on individual mode choice. An empirical study of the houstongalveston metropolitan area," International Journal of Sustainable Transportation, vol. 8, no. 6, pp. 447-470, 2014.

[45] J.-J. Lin and H.-T. Chang, "Built environment effects on children's school travel in Taipai: independence and travel mode," Urban Studies, vol. 47, no. 4, pp. 867-889, 2010.

[46] T. Schwanen and P. L. Mokhtarian, "What if you live in the wrong neighborhood? The impact of residential neighborhood type dissonance on distance traveled," Transportation Research Part D: Transport and Environment, vol. 10, no. 2, pp. 127-151, 2005.

[47] R. Cervero, "Built environments and mode choice. Toward a normative framework," Transportation Research Part D: Transport and Environment, vol. 7, no. 4, pp. 265-284, 2002.

[48] D. A. Rodríguez and J. Joob, "The relationship between nonmotorized mode choice and the local physical environment," Transportation Research Part D: Transport and Environment, vol. 9, no. 2, pp. 151-173, 2004.

[49] R. Cervero and K. Kockelman, "Travel demand and the 3Ds. Density, diversity, and design," Transportation Research Part D: Transport and Environment, vol. 2, no. 3, pp. 199-219, 1997.

[50] R. Ewing and R. Cervero, "Travel and the built environment," Journal of the American Planning Association, vol. 76, no. 3, pp. 265-294, 2010.

[51] H. Meurs and R. Haaijer, "Spatial structure and mobility," Transportation Research Part D: Transport and Environment, vol. 6, no. 6, pp. 429-446, 2001.

[52] R. Kitamura, P. L. Mokhtarian, and L. Laidet, "A micro-analysis of land use and travel in five neighborhoods in the San Francisco Bay Area," Transportation, vol. 24, no. 2, pp. 125-158, 1997.

[53] S. Handy, X. Cao, and P. Mokhtarian, "Correlation or causality between the built environment and travel behavior? Evidence from Northern California," Transportation Research Part D: Transport and Environment, vol. 10, no. 6, pp. 427-444, 2005.

[54] X. Cao, P. L. Mokhtarian, and S. L. Handy, "Neighborhood design and vehicle type choice. Evidence from Northern California," Transportation Research Part D: Transport and Environment, vol. 11, no. 2, pp. 133-145, 2006.

[55] X. J. Cao, P. L. Mokhtarian, and S. L. Handy, "The relationship between the built environment and nonwork travel: a case study of Northern California," Transportation Research Part A: Policy and Practice, vol. 43, no. 5, pp. 548-559, 2009.

[56] Y. O. Susilo, K. Williams, M. Lindsay, and C. Dair, “The influence of individuals' environmental attitudes and urban design 
features on their travel patterns in sustainable neighborhoods in the UK," Transportation Research Part D: Transport and Environment, vol. 17, no. 3, pp. 190-200, 2012.

[57] D. McFadden, "Economic choices," American Economic Review, vol. 91, no. 3, pp. 351-378, 2001.

[58] T. Gärling, "Behavioral assumptions overlooked in travelchoice modelling," in Transport Modelling, J. Ortuzar, S. JaraDiaz, and D. Hensher, Eds., pp. 3-18, Pergamon, Oxford, UK, 2008.

[59] M. Ben-Akiva, D. Mcfadden, K. Train et al., "Hybrid choice models: progress and challenges," Marketing Letters, vol. 13, no. 3, pp. 163-175, 2002.

[60] D. Bolduc, M. Ben-Akiva, J. Walker, and A. Michaud, "Hybrid choice models with logit kernel: applicability to large scale models," in Integrated Land-Use and Transportation Models: Behavioural Foundations, M. E. H. Lee-Gosselin and S. T. Doherty, Eds., Default Book Series, pp. 275-302, 2005.

[61] P. Mariel, J. Meyerhoff, and S. Hess, "Heterogeneous preferences toward landscape externalities of wind turbines-combining choices and attitudes in a hybrid model," Renewable and Sustainable Energy Reviews, vol. 41, pp. 647-657, 2015.

[62] D. Bolduc, N. Boucher, and R. Alvarez-Daziano, "Hybrid choice modeling of new technologies for car choice in Canada," Transportation Research Record: Journal of the Transportation Research Board, vol. 2082, pp. 63-71, 2008.

[63] Central bank of the Islamic republic of Iran, 2015, http://www .cbi.ir/default_en.aspx.

[64] P. Black and E. Street, "The power of perceptions: exploring the role of urban design in cycling behaviours and healthy ageing," Transportation Research Procedia, vol. 4, pp. 68-79, 2014.

[65] L. Ma and J. Dill, "Associations between the objective and perceived built environment and bicycling for transportation," Journal of Transport \& Health, vol. 2, no. 2, pp. 248-255, 2015.

[66] L. Ma, J. Dill, and C. Mohr, “The objective versus the perceived environment: what matters for bicycling?” Transportation, vol. 41, no. 6, pp. 1135-1152, 2014.

[67] A. L. Oyeyemi, C. M. Ishaku, B. Deforche, A. Y. Oyeyemi, I. de Bourdeaudhuij, and D. van Dyck, "Perception of built environmental factors and physical activity among adolescents in Nigeria," The International Journal of Behavioral Nutrition and Physical Activity, vol. 11, article 56, 2014.

[68] D. A. Rodríguez, L. Merlin, C. G. Prato et al., "Influence of the built environment on pedestrian route choices of adolescent girls," Environment and Behavior, vol. 47, no. 4, pp. 359-394, 2015.

[69] D. Saarloos, J.-E. Kim, and H. Timmermans, "The built environment and health: introducing individual space-time behavior," International Journal of Environmental Research and Public Health, vol. 6, no. 6, pp. 1724-1743, 2009.

[70] Atlas of Tehran Metropolis, 2016, http://atlas.tehran.ir/en/ PopulationMigration.aspx.

[71] Tehran Municipality Portal, 2016, http://www.tehran.ir/.

[72] “2016 Statistical Center of Iran," https://www.amar.org.ir/.

[73] A. R. Mamdoohi, M. Yazdanpanah, A. Taherpour, and M. Saffarzadeh, "An analysis of resident and non-resident air passenger," International Journal of Transpotation Engineering, vol. 2, no. 1, 2013.

[74] M. Bierlaire, PythonBiogeme: a short introduction, Report TRANSP-OR 160706 ,Series on Biogeme. Transport and Mobility Laboratory, School of Architecture, Civil and Environmental Engineering, Ecole Polytechnique Fédérale de Lausanne, Switzerland, 2016.
[75] M. E. Ben-Akiva and S. R. Lerman, "Discrete choice analysis," in Theory and Application to Travel Demand/Moshe Ben-Akiva, Steven R. Lerman, vol. 9 of MIT Press Series in Transportation Studies, MIT Press, Cambridge, Mass, USA, 1985.

[76] F. Koppelman and C. Bhat, A Self Instructing Course in Mode Choice Modeling: Multinomial and Nested Logit Models, prepared for U.S. Department of Transportation, Federal Transit Administration, 2006.

[77] K. E. Train, Discrete choice methods with simulation, Cambridge University Press, Cambridge, New York, U.S.A, Second edition, 2009.

[78] V. M. Danthurebandara, M. Vandebroek, and J. Yu, "Integrated mixed logit and latent variable models," Marketing Letters, vol. 24, no. 3, pp. 245-259, 2013.

[79] X. Fu and Z. Juan, "Estimation of multinomial probit-kernel integrated choice and latent variable model: comparison on one sequential and two simultaneous approaches," Transportation, pp. 1-26, 2015.

[80] R. Hurtubia, M. H. Nguyen, A. Glerum, and M. Bierlaire, "Integrating psychometric indicators in latent class choice models," Transportation Research Part A: Policy and Practice, vol. 64, pp. 135-146, 2014.

[81] M. Kamargianni, M. Ben-Akiva, and A. Polydoropoulou, "Incorporating social interaction into hybrid choice models," Transportation, vol. 41, no. 6, pp. 1263-1285, 2014.

[82] J. Kim, S. Rasouli, and H. Timmermans, "Expanding scope of hybrid choice models allowing for mixture of social influences and latent attitudes. Application to intended purchase of electric cars," Transportation Research Part A: Policy and Practice, vol. 69, pp. 71-85, 2014.

[83] J. Kim, S. Rasouli, and H. Timmermans, "Hybrid choice models: principles and recent progress incorporating social influence and nonlinear utility functions," Procedia Environmental Sciences, vol. 22, pp. 20-34, 2014.

[84] S. Raveau, R. Álvarez-Daziano, M. F. Yáñez, D. Bolduc, and J. De Dios Ortúzar, "Sequential and simultaneous estimation of hybrid discrete choice models: some new findings," Transportation Research Record, no. 2156, pp. 131-139, 2010.

[85] E. Sottile, I. Meloni, and E. Cherchi, "A hybrid discrete choice model to assess the effect of awareness and attitude towards environmentally friendly travel modes," Transportation Research Procedia, vol. 5, pp. 44-55, 2015.

[86] Y. Motoaki and R. A. Daziano, "Assessing goodness of fit of hybrid choice models," Transportation Research Record: Journal of the Transportation Research Board, vol. 2495, 2015. 


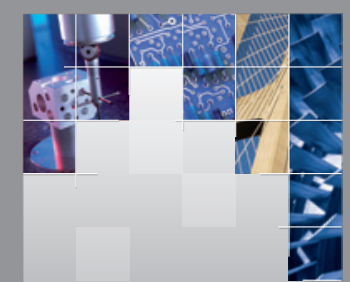

\section{Enfincering}
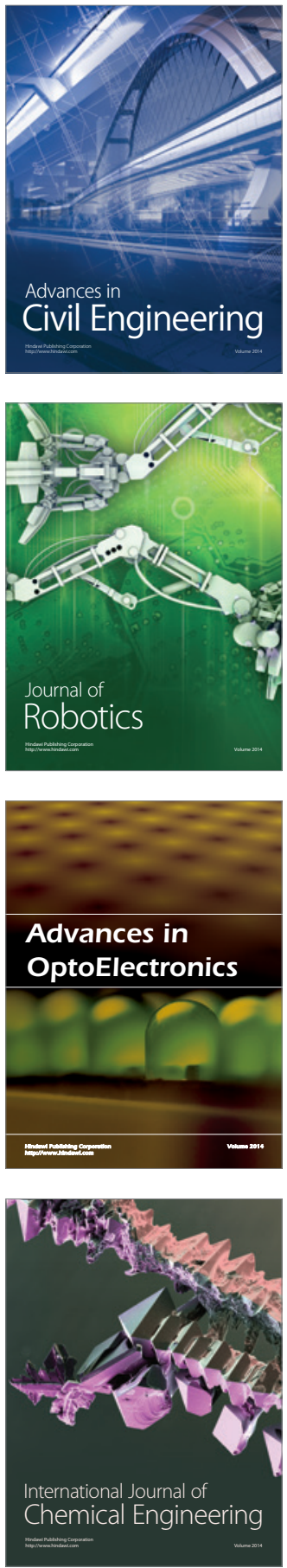

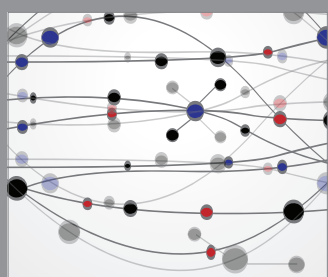

The Scientific World Journal

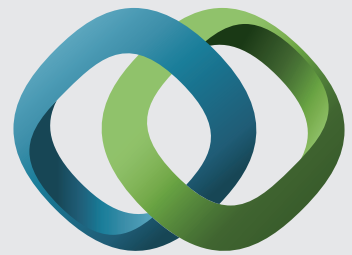

\section{Hindawi}

Submit your manuscripts at

https://www.hindawi.com
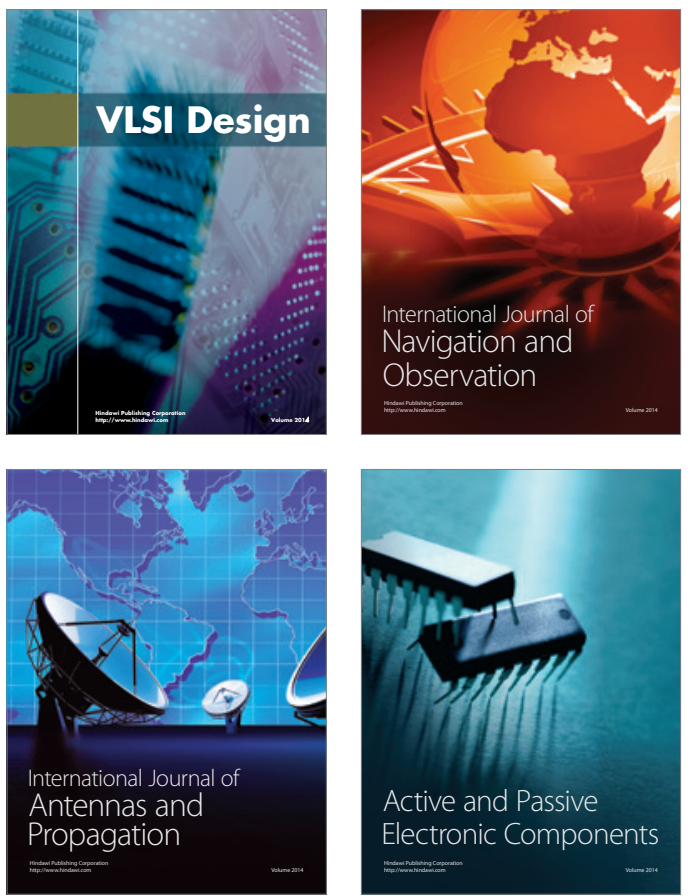
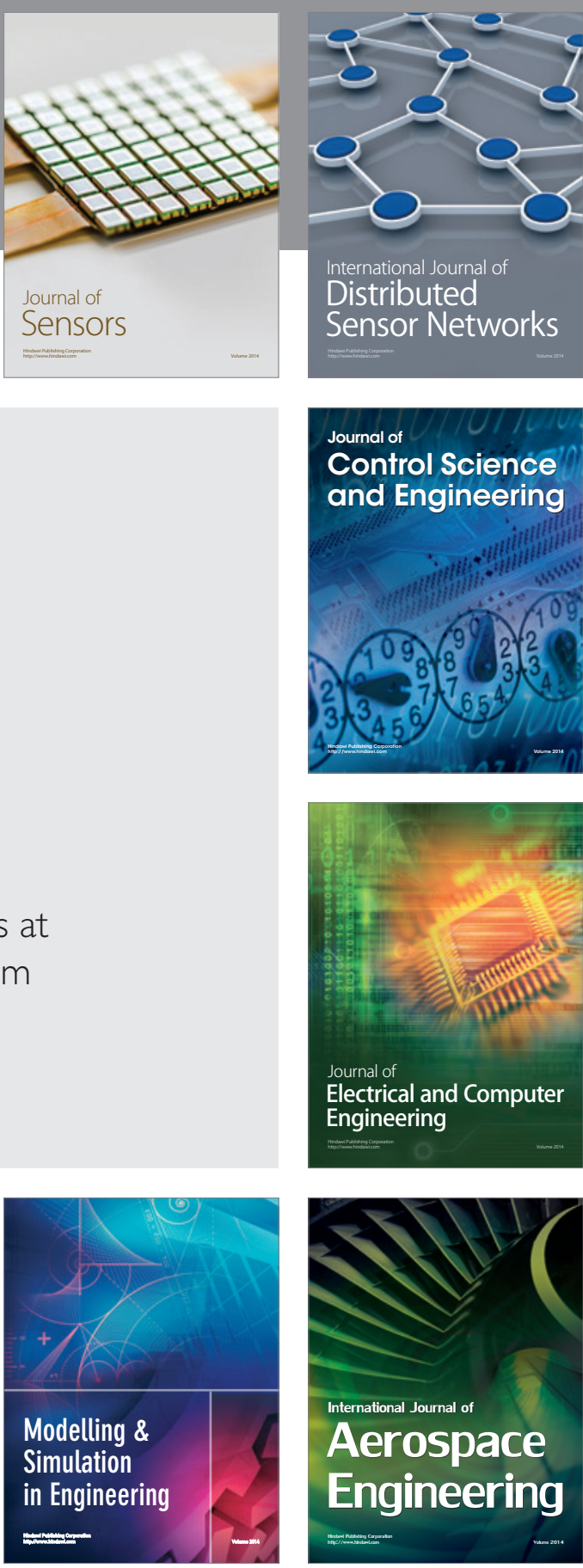

International Journal of

Distributed

Sensor Networks

$-$

Joumal of

Control Science

and Engineering
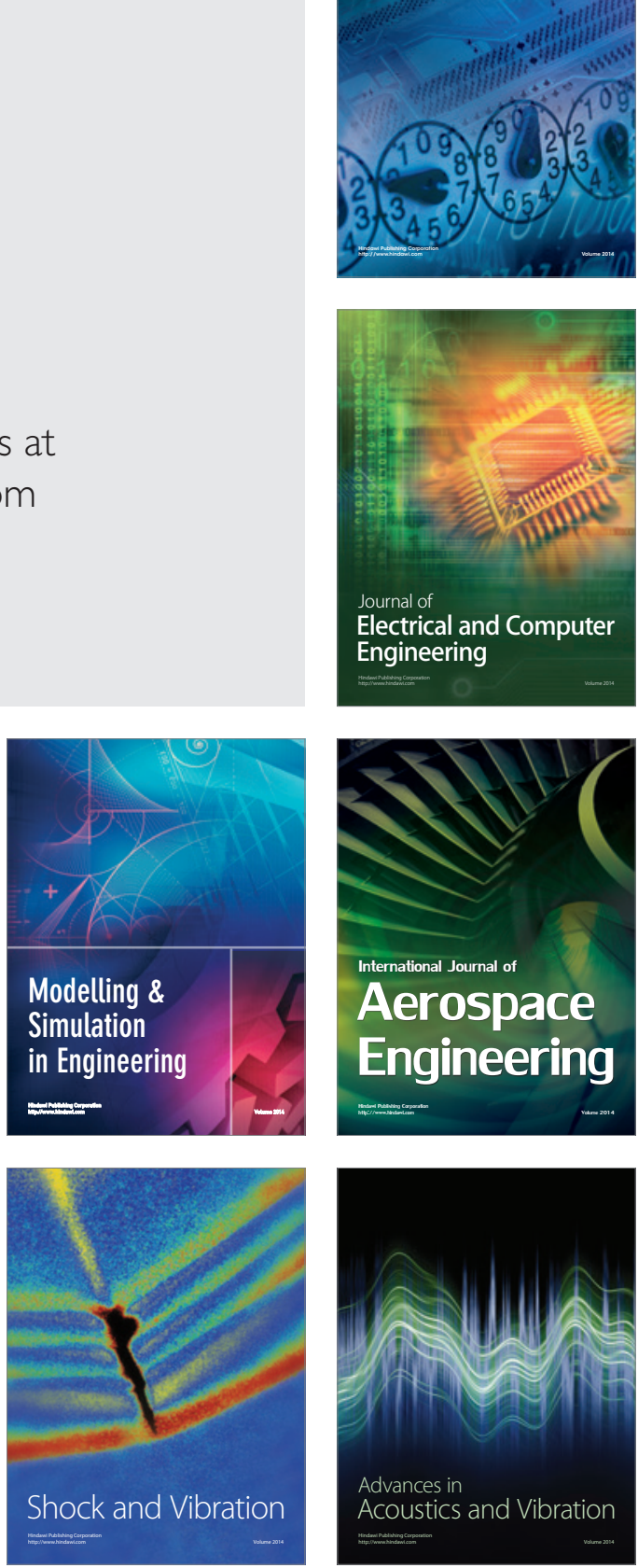